\title{
Recruitment rate, feasibility and safety of power training in individuals with Parkinson's disease: a proof-of-concept study
}

\begin{abstract}
Lidiane O. Lima ${ }^{1}$, Fátima Rodrigues-de-Paula ${ }^{2}$
ABSTRACT | Background: It has been suggested that power training should be implemented in interventions in Parkinson's disease (PD). However, it is necessary to determine the feasibility and safety of training rapid movements in such individuals. Objectives: To determine the rate of recruitment of potential participants, the rate of attendance at training sessions, the levels of adherence to the intervention, and the rate of adverse events. Method: Patients with PD, users of the national public health system underwent power training of the lower limb muscles three times a week for 10 weeks. The number of people who were screened and recruited was recorded, as well as the rate of attendance at the training sessions and adherence to the intervention protocol. Safety was assessed by the presence of adverse events, pain, number of falls, and risk of injury associated with the intervention. Results: Over the course of eight months, 62 individuals were screened and only 13 completed the program. The rates of attendance and adherence were $88 \%$ and $97 \%$, respectively. There were no adverse events during training. Two participants reported joint pain and one reported falls during the training period. Conclusions: The recruitment rate was low due to the subjects' difficulties with transportation and lack of interest. The high rates of adherence and attendance and the absence of adverse events suggest that power training is feasible and safe in PD.
\end{abstract}

Keywords: Parkinson's disease; safety; rehabilitation; physical therapy.

\section{HOW TO CITE THIS ARTICLE}

Lima LO, Rodrigues-de-Paula F. Recruitment rate, feasibility and safety of power training in individuals with Parkinson's disease: a proof-of-concept study. Braz J Phys Ther. 2013 Jan-Feb; 17(1):49-56. http://dx.doi.org/10.1590/S1413-35552012005000069

\section{- Introduction}

Dopaminergic loss in subjects with Parkinson's Disease (PD) results in reduction in corticospinal activaction with deficit in the recruitment of motor units, contributing to muscle weakness and bradykinesia ${ }^{1}$. Moreover, tissue changes such as the selective loss of type II muscle fibers in subjects with PD can contribute to the inability to generate strength during the performance of fast movements ${ }^{2}$. Muscle power is the measure of the capacity to generate strength quickly ${ }^{3}$ and this is reduced in $\mathrm{PD}^{4}$. Such reduction has been attributed to a decline in muscle strength $^{3}$ and to bradykinesia ${ }^{3,4}$, and it seems to be associated with slow gait speed and the occurrence of falls in subjects with PD .

Some authors suggest that intervention strategies created to increase muscle power through fast movements should be implemented in exercise programs for $\mathrm{PD}^{5}$. Power training programs with low load improve strength, muscle power, balance, contraction speed, and time of movement in older adults $^{6-8}$. In these subjects, loads equal to $40 \%$ of one maximal resistance (1MR) were able to increase muscle power because of the gains in movement speed $^{8,9}$.

Power training has been shown to be safe and well tolerated in older adults ${ }^{10}$, however there is a need to determine possible adverse events associated with the training of fast movements in frail, sedentary older adults with functional deficits ${ }^{10,11}$. There is still no evidence that this kind of exercise can be safe and tolerated by subjects with PD, although safety is the main concern for these subjects when deciding to participate in a clinical trial ${ }^{12}$.

Proof-of-concept clinical trials generate the first evidence that a treatment might be effective, provide information about tolerance and adverse events associated with this treatment ${ }^{13}$, and contribute to the planning of controlled randomized trials ${ }^{13,14}$. In addition, information about attendance and

\footnotetext{
${ }^{1}$ Postgraduate Program in Rehabilitation Sciences, Universidade Federal de Minas Gerais (UFMG), Belo Horizonte, MG, Brazil 
adherence is important because it reflects the treatment's adequacy for a targeted population and should be considered during the development of training protocols for patients with $\mathrm{PD}^{15,16}$. Finally, it is necessary to understand the factors that could potentially interfere in the process of selection and recruitment of research subjects with PD users of the national public health system.

Therefore, the overall aim of the present study was to investigate the feasibility and safety of lower limb power training in subjects with PD. Specifically, the intent was to determine the rate of recruitment, the rate of attendance at the training sessions, the level of adherence to the proposed intervention protocols, and the rate of adverse events related to training.

\section{Method}

The current study was developed with subjects with PD recruited according to the following inclusion criteria: diagnosis of idiopathic PD, age of 50 years and over, classification on the Hoehn \& Yahr Scale $(\mathrm{HY})^{17}$ as stage 1 to 3 , regular use of anti-parkinsonian medication, score of more than 24 on the Mini Mental State Exam (MMEE) ${ }^{18}$, ability to walk 14 meters independently and sign the informed consent form. Subjects were excluded if they had adverse clinical conditions that prevented their participation in the proposed protocol, such as uncontrolled arterial hypertension and other neurological, orthopedic or rheumatologic disorders. Subjects were also excluded if they had undergone surgical intervention for PD, received physical therapy treatment or exercised regularly for at least two months before the start of this study. The present research had the approval of the Research Ethics Committee (ETIC 000/10) of Universidade Federal de Minas Gerais (UFMG), Belo Horizonte, MG, Brazil, and free informed consent was obtained from all of the participants.

Subjects with PD received training three times a week for ten weeks, with sessions lasting 60 minutes. The power training sessions were conducted by a trained physical therapist in groups of up to four participants. The lower limb muscle groups trained were the hip flexors, extensors, adductors, abductors; knee flexors and extensors; ankle dorsiflexors; and plantar flexors. Subjects were instructed to perform each movement 'as fast as possible' in the concentric phase of the exercise.

Free weights and elastic bands (Thera-bands ${ }^{\circledR}$ ) were used for training. For the free weights, the load was set at $40 \%$ of $1 \mathrm{MR}^{8,9}$ across all exercises and readjusted every two weeks. MR was defined as the maximal load that can be raised once throughout the whole range of motion without compensation ${ }^{5}$. With the elastic bands, progression was made when subjects were able to perform three sets of ten repetitions with slight fatigue in the last set ${ }^{7}$. Three sets of ten repetitions were performed for each exercise with 1-2 minutes of rest between them, according to the protocol proposed by the American College of Sports Medicine $(\mathrm{AMCS})^{19}$. A vest with four front pockets and four back pockets was designed to hold the free weights during the exercises for the plantar flexors. Blood pressure and heart rate were measured before, during, and after each training session.

\section{Recruitment assessment}

Recruitment was done at the Movement Disorders Clinic of the University. This clinic is a center of reference in the southeastern part of the country in research and assistance to subjects with various movement disorders, such as parkinsonisms ${ }^{20}$. The clinic's patients use the national public health system (Sistema Único de Saúde-SUS).

Subject recruitment was conducted by physical therapy students capable of evaluating the eligibility criteria while patients waited to be seen by the neurologist. Data were recorded for the number of eligible subjects and for the reasons for ineligibility. Similarly, data were recorded for the reason given by eligible subjects for declining to participate in the study.

\section{Assessment of attendance and adherence}

Data on attendance and adherence to training protocol were collected by the physical therapist during the period of intervention. At each training session, the subjects' presence or absence was recorded, as well as the reason for the absence. The total number of training sessions available varied slightly among the subjects due to the public holidays during the period of intervention.

Treatment adherence was determined by the number of sessions completed in full (60 minutes). The number of incomplete sessions and the reasons for not completing the session were recorded. The reason for the absence was identified on the same day during a phone call from the researchers.

\section{Safety evaluation}

The safety of the power training program was assessed on the basis of adverse events, pain during and after the activity, number of falls, and risk of 
injury associated with the treatment. Adverse events were monitored and recorded at each session and defined as injury or complaint related to the treatment if they required that the subject seek professional help or limited his/her activities ${ }^{21}$. Throughout each session, the supervising physical therapist asked each subject about the presence of any discomfort and pain related to the activity. In the presence of pain, the Visual Analogue Scale was used. Risk of injury was defined as the ratio of number of subjects with complaints of adverse events to the total number of subjects $^{22}$.

The Borg Scale of Perceived Exertion ${ }^{23}$ was used after each training session in order to investigate the subject's tolerance to the exercise. The minimal score (6) refers to the perception of no effort during exercise, and the highest score (20) reflects maximal effort.

\section{Statistical analysis}

Descriptive statistics such as mean (standard deviation) and percentage were performed for the proposed variables.

\section{- Results}

A total of 13 subjects with PD (eight men and five women), with a mean age of $63.8 \pm 12.3$ years $(50-87)$, participated in the training program. In $8 \%$, the HY classification was equal to 1.5 ; in $38 \%, \mathrm{HY}=2.5$; and $16 \%, \mathrm{HY}=3$. The mean length of evolution of the disease was of $7.9 \pm 4.6$ years (2-16).

Table 1 shows the socio-economic and cultural profile of the subjects. Most of them were married, lived with their relatives, and had an income of less than 2.5 times the minimum wage. All subjects made use of levodopa-based medication combined with other anti-parkinsonian medications, such as dopaminergic agonists, anticolinergics, and amantadine. The most frequent health condition was arterial hypertension, present in five participants (38\%), followed by osteoarthritis in four (31\%), and depression in three $(23 \%)$.

\section{Recruitment}

A total of 62 subjects with PD were selected for the verification of eligibility between March and October/2011. Of these, 19 (31\%) were excluded because they did not fulfill the inclusion criteria (Table 2). The major reasons for the exclusion were: uncontrolled arterial hypertension, recent orthopedic surgery, and early onset PD. Of the 43 eligible subjects, 36 (84\%) refused to participate in the study, and the reasons are shown in Table 3. The most significant reason was the lack of financial resources for transportation and access to the training location.

In short, seven (11\%) subjects were eligible and consented to participate in the study. The nine subjects who reported lack of money for transportation had their expenses covered by the researchers, reaching a total of 16 subjects. Of these, three had to interrupt their training on the third, fifth, and sixth week of the protocol, despite attendance above $89 \%$ until the date they left the study. The reasons for withdrawing

Table 1. Socio-economical and cultural characteristics of the subjects $(n=13)$.

\section{Variable}

Marital status

Married

Single, widowed or divorced

Living arrangements

With family

Alone

Educational Level (years of study)

$<9$ years

9 years

12 years

Family income

1 - 3 x minimum wage

4 - 6 x minimum wage

Occupation

Retirees and pensioners

Table 2. Number (\%) of individuals with PD who were screened but excluded $(n=19)$.

\begin{tabular}{lc}
\hline \multicolumn{1}{c}{ Reason } & Excluded (\%) \\
Patients with adverse health conditions & $4(21)$ \\
Early onset PD (<50 years) & $4(21)$ \\
Current physical therapy treatment & $3(16)$ \\
$\begin{array}{l}\text { Patients on waiting list or submitted to } \\
\text { surgery for PD }\end{array}$ & $3(16)$ \\
MMSE (<24) & $3(16)$ \\
Dementia/Psychiatric symptoms & $2(10)$ \\
\hline
\end{tabular}

MMSE: Mini-Mental State Examination. 
Table 3. Number (\%) of individuals with PD who declined to participate $(n=36)$.

\section{Reason}

Lack of money for transportation

Lack of interest (motivation)

Lack of caregiver/partner support

Living in other cities

Disliked exercise/physical therapy

were personal problems, such as a relative diagnosed with a serious illness or involved in an accident and the need to take care of grandchildren.

\section{Attendance}

The rate of attendance was of $88 \pm 7.3 \%$, thus 328 of the 373 available sessions were attended by the subjects. The main reasons for the absence were: health problems, such as feeling unwell and having influenza (35\%); difficulties with public transportation (overcrowding, lack and bad conditions of the vehicles) (32\%); family problems $(28 \%)$, and travel for religious purposes $(5 \%)$. Eight subjects $(61 \%)$ attended $89 \%$ or more of the available sessions.

\section{Adherence}

Of the 328 sessions attended by the subjects, 318 were completed, and ten were not completed due to health reasons. Four subjects did not complete the total time of the training session due to motor fluctuations (70\%) and physical feeling of indisposition.

\section{Safety}

Adverse events did not happen during training. Two subjects reported knee and back pain related to preexisting osteoarthritis. The average intensity of pain was four (3-5) according to the Visual Analogue Scale, therefore it was not necessary to exclude the subjects from the program. In one of them, the pain persisted in the following session, and it was necessary to reduce the intensity of the exercises, however there was no pain in the subsequent sessions. One participant reported two falls that occurred at home during the ten-week training period but without consequences or need for medical attention. The risk of injury was null, considering the absence of occurrence of adverse events. Although arterial hypertension was the most frequent health condition, no cardiovascular problems were reported during the intervention period. The average perceived exertion was $12.8 \pm 1.1$ (11-14), which corresponds to 'somewhat hard' on the Borg Scale.

\section{Discussion}

To our knowledge, this is the first study to investigate the feasibility and safety of a power training program in subjects with mild to moderate PD. The data concerning the recruitment rates, attendance, adherence, and safety of the subjects will be discussed next.

\section{Recruitment}

It has been pointed out that the main obstacle to the implementation of clinical experiments in PD is patient recruitment ${ }^{12,24}$. The present study showed a low recruitment rate of $11 \%$ during the period of eight months. Considering the characteristics of the recruitment environment and of the direct access of the researchers to the subjects with PD, a higher success rate was expected. Several reasons have been cited for the low rates of recruitment in feasibility studies in PD. Ashburn et al. ${ }^{24}$ cited the inclusion of subjects with $\mathrm{PD}$ who were physically and cognitively capable of participating in an exercise program for balance improvement as an obstacle to recruitment, which had a success rate of $13 \%$ in a period of one year of study. In the study by Keus et al..$^{25}$, the effectiveness of a physical therapy program based on exercises for posture, balance, and gait was evaluated, and the recruitment rate was $14 \%$, although the period had not been defined. According to the authors, the greatest difficulty was the refusal of subjects with PD to participate because of the possibility of being allocated to the control group, with no treatment $\mathrm{t}^{25}$.

In the present study, the main obstacles to recruitment were the lack of financial resources for transportation to the training location, the lack of interest, and the lack of a caregiver/partner. The lack of interest was the second most frequent reason for not joining the study. The fact that the recruitment was performed before the doctor's appointment may have been a limitation of the study, since there was no referral from the neurologist. Some studies suggested that the recommendation of a neurologist plays a major role in a PD subject's decision to participate in an exercise program ${ }^{12,26}$. Valadas et al. ${ }^{12}$ showed that the neurologist's recommendation of a clinical trial had a more determining role in that decision 
than the severity of symptoms and free medication and treatment. It is possible that the emphasis given by the clinical neurologist to the importance of the participation in exercise programs can maximize the recruitment rate of these programs.

In addition to having a low income, the participants came from the suburbs and had to use one or more means of public transportation to get to the city center, where the training was conducted. The distance between their homes and the training location in addition to mobility impairments (e.g. freezing, bradykinesia, fear of falling) meant that the subject required a caregiver/partner for the trip. Recently, another study developed in Brazil ${ }^{27}$ also cited lack of money for transport as the main barrier to participation and attendance by subjects after stroke. Studies that investigated the sociodemographic profile of SUS users in different regions in Brazil reported that such users have low income, low educational levels, and greater need for health support ${ }^{28,29}$.Therefore, to conduct future studies, it is crucial that researchers secure sufficient funding for transportation so that subjects with PD who use SUS can take part in the research, thus improving recruitment rates.

\section{Attendance}

This study showed high attendance at the intervention sessions, close to the rate reported by studies on strength training in PD, which ranged from $89 \%{ }^{30}$ to $92 \%{ }^{31}$. A qualitative analysis of progressive resistance programs for individuals with PD indicated that socialization with people at the same stage of the disease was the most important motivating factor for attendance by these subjects ${ }^{26}$. It is possible that the group power training in the present study fostered integration among the participants, motivating them to continue with the program. Researchers and clinicians should consider the group approach in PD interventions in order to generate greater social interaction and, consequently, better attendance.

Three participants had the flu during the training period, which coincided with the winter, and the season's typically low temperatures may have contributed to the symptoms. Moreover, the difficulties with public transport (e.g. overcrowding, poor maintenance, and limited number of vehicles) were also cited as justification for absences. A recent systematic review showed that the lack of transportation was the most common reason given by subjects with PD for discontinuing their participation in different training program ${ }^{16}$. Most participants lived far from the training location and relied solely on public transportation. According to Ribeiro et al. ${ }^{28}$, SUS users seek less preventive intervention and rehabilitation treatment than nonusers. It is possible that the lack or precariousness of public transportation options available to these individuals is one of the aspects that influences the decision to participate in treatments that require more frequent weekly attendance, as in the case of physical therapy.

\section{Adherence}

One of the subjects did not complete five of the sessions because of an 'off period' characterized by the early end of the effect of medication. According to Ahlskog and Muenter ${ }^{32}$, after four to six years of levodopa, $40 \%$ of users exhibit motor fluctuations. Considering the prevalence of this drug complication over the course of the disease, studies should report its occurrence during any type of intervention. In addition, more flexible scheduling of training sessions can increase adherence of individuals with PD to exercise programs.

\section{Safety}

A recent study suggested that power training can be implemented in physically active older adults, but may not be adequate to those considered fragile and sedentary ${ }^{11}$. The reason given for this was the vigorous nature of power training, which requires physical fitness in order to allow adequate adaptation of the tissues ${ }^{11}$. However, in this study, no adverse events related to power training in subjects with PD were reported. Although the subjects were sedentary and some had balance deficits, there was no serious discomfort or injury. The absence of adverse events might be attributed to the load used. Exercises with light load have been shown to be effective, better tolerated, and less likely to cause injury during training in older adults ${ }^{10}$. The study by de Vos et al..$^{10}$ on power training in older adults showed that low loads (20\% of 1RM) increased peak power just as moderate $(50 \% 1 \mathrm{RM})$ and high $(80 \%$ 1RM) loads, with a lower occurrence of injury than in others.

Some participants with a history of osteoarthritis reported pain during exercise. It has been suggested that strength exercises with low loads are less likely to aggravate the symptoms of illnesses such as osteoarthritis [OA] in older adults ${ }^{33}$. However, it is necessary to consider the possibility that training exacerbates pain and the fact that $\mathrm{OA}$ has been singled out as one of the most frequent causes of chronic 
pain in patients with PD and may be exacerbated by the disease ${ }^{34}$. Therefore, a careful joint assessment is recommended prior to the start of the exercise program as well as greater care during its execution, specifically with range of motion exercises, in order to avoid the worsening of pain.

The participant who reported falls early in the treatment had already fallen in the previous year and did not suffer more falls in the last five weeks of intervention. Freezing is a common disorder in the gait of subjects with PD and contributes to the occurrence of falls as much as postural instability ${ }^{35}$. Power training can improve the ability to react quickly to unexpected disturbances and contribute to greater agility, minimizing the effects of freezing and the occurrence of falls in PD. However, this aspect needs to be investigated further.

Given the need for fast and explosive performance of the exercises, individuals can report a significant effort due to bradykinesia. In the present study, however, the subjects' average score on the Borg Perceived Exertion Scale indicated that the perceived exertion was close to 'somewhat heavy'. Sayers' showed similar results after a power training with $40 \%$ of load in older adults. The findings of this study suggest that fast, intense, and explosive movements were perceived as tolerable by individuals with mild to moderate $\mathrm{PD}$, contributing to greater adherence to the program. Future studies are needed to investigate perceived exertion in power training in individuals at more advanced stages of the disease, whose motor impairment due to more pronounced rigidity and bradykinesia may require greater effort during the exercises.

The results showed a low recruitment rate due to difficulties with transportation and lack of interest of individuals with PD in participating in the study. The high rates of attendance and adherence combined with the absence of adverse events indicate that power training is feasible and safe in PD.

\section{Acknowledgements}

To Conselho Nacional de Desenvolvimento Científico e Tecnológico [National Council of Scientific and Technological Development] (CNPq) and Fundação de Amparo à Pesquisa do Estado de Minas Gerais [Research Foundation of the State of Minas Gerais] (FAPEMIG).

\section{References}

1. David FJ, Rafferty MR, Robichaud JA, Prodoehl J, Kohrt WM, Vaillancourt DE, et al. Progressive resistance exercise and Parkinson's disease: a review of potential mechanisms. Parkinsons Dis. 2012;2012: 124527. PMid:22191068 PMCid:PMC3236435. http://dx.doi. org/10.1155/2012/124527

2. Pang MY, Mak MK. Influence of contraction type, speed, and joint angle on ankle muscle weakness in Parkinson's disease: implications for rehabilitation. Arch Phys Med Rehabil 2012. PMid:22705465. http://dx.doi. org/10.1016/j.apmr.2012.06.004

3. Paul SS, Canning CG, Sherrington C, Fung VSC. Reduced muscle strength is the major determinant of reduced leg muscle power in Parkinson's disease. Parkinsonism Relat Disord. 2012;18(8):974-7. PMid:22682756. http://dx.doi. org/10.1016/j.parkreldis.2012.05.007

4. Allen NE, Canning CG, Sherrington C, Fung VSC Bradykinesia, muscle weakness and reduced muscle power in Parkinson's disease. Mov Disord. 2009;24(9):1344-51. PMid:19425085. http://dx.doi.org/10.1002/mds.22609

5. Allen NE, Sherrington C, Canning CG, Fung VSC. Reduced muscle power is associated with slower walking velocity and falls in people with Parkinson's disease. Parkinsonism Relat Disord. 2010;16(4):261-6. PMid:20117036, http:// dx.doi.org/10.1016/j.parkreldis.2009.12.011

6. Orr R, de Vos NJ, Singh NA, Ross DA, Stavrinos TM, Fiatarone-Singh MA. Power training improves balance in healthy older adults. J Gerontol A Biol Sci Med Sci. 2006;61(1):78-85. PMid:16456197.

7. Webber SC, Porter MM. Effects of ankle power training on movement time in mobility-impaired older women. Med Sci Sports Exerc. 2010;42(7):1233-40. PMid:20019625. http://dx.doi.org/10.1249/MSS.0b013e3181cdd4e9

8. Sayers SP, Gibson KA. Comparison of high-speed power training and traditional slow-speed resistance training in older men and women. J Strength Cond Res. 2010;24(12):3369-80. PMid:21068681.

9. Sayers SP. High-speed power training: a novel approach to resistance training in older men and women. A brief review and pilot study. J Strength Cond Res. 2007;21(2):518-26. PMid:17530980.

10. de Vos NJ, Singh NA, Ross DA, Stavrinos TM, Orr R, Fiatarone Singh MA. Optimal load for increasing muscle power during explosive resistance training in older adults. J Gerontol A Biol Sci Med Sci. 2005;60(5):638-47. PMid:15972618.

11. Tschopp M, Sattelmayer MK, Hilfiker R. Is power training or conventional resistance training better for function in elderly persons? A meta-analysis. Age Ageing. 2011;40(5):549-56. PMid:21383023. http:// dx.doi.org/10.1093/ageing/afr005

12. Valadas A, Coelho M, Mestre T, Guedes LC, Finisterra M, Noronha A, et al. What motivates Parkinson's disease patients to enter clinical trials? Parkinsonism Relat 
Disord. 2011;17(9):667-71. PMid:21715213. http://dx.doi. org/10.1016/j.parkreldis.2011.05.023

13. Fardon T, Haggart K, Lee DK, Lipworth BJ. A proof of concept study to evaluate stepping down the dose of fluticasone in combination with salmeterol and tiotropium in severe persistent asthma. Respir Med. 2007;101(6):1218-28. PMid:17178217. http:// dx.doi.org/10.1016/j.rmed.2006.11.001

14. Thabane L, Ma J, Chu R, Cheng J, Ismaila A, Rios LP, et al. A tutorial on pilot studies: the what, why and how. BMC Med Res Methodol. 2010;10:1-10. PMid:20053272. http://dx.doi.org/10.1186/1471-2288-10-1

15. McGinley JL, Martin C, Huxham FE, Menz HB, Danoudis M, Murphy AT, et al. Feasibility, safety, and compliance in a randomized controlled trial of physical therapy for Parkinson's disease. Parkinsons Dis. 2012;2012:795294. PMID:22191076 PMCid:PMC3236432. http://dx.doi. org/10.1155/2012/795294

16. Allen NE, Sherrington C, Suriyarachchi GD, Paul SS, Song J, Canning CG. Exercise and motor training in people with Parkinson's disease: a systematic review of participant characteristics, intervention delivery, retention rates, adherence, and adverse events in clinical trials. Parkinsons Dis. 2012;2012:854328. PMid:22191077 PMCid:PMC3236465. http://dx.doi. org/10.1155/2012/854328

17. Hoehn M, Yahr MD. Parkinsonism: onset, progression and mortality. Neurology. 1967;17(5):427-42. Pmid:6067254. http://dx.doi.org/10.1212/WNL.17.5.427

18. Bertolucci PHF, Brucki SMD, Campacci SR, Juliano Y. O mini-exame do estado mental em uma população geral: impacto da escolaridade. Arq Neuropsiquiatr. 1994;52(1):1-7. http://dx.doi.org/10.1590/ S0004-282X1994000100001

19. Kraemer WJ, Adams K, Cafarelli E, Dudley GA, Dooly C, Feigenbaum MS, et al. American College of Sports Medicine position stand. Progression models in resistance training for healthy adults. Med Sci Sports Exerc. 2002;34(2):364-80. PMid:11828249.

20. Camargos ST, Dornas LO, Momeni P, Lees A, Hardy J, Singleton A, et al. Familial Parkinsonism and early onset Parkinson's disease in a Brazilian movement disorders clinic: phenotypic characterization and frequency of SNCA, PRKN, PINK1, and LRRK2 mutations. Mov Disord. 2009;24(5):662-6. PMid:19205068 PMCid:PMC2850048. http://dx.doi.org/10.1002/ mds. 22365

21. Canning CG, Sherrington C, Lord SR, Fung VSC, Close JCT, Latt MD, et al. Exercise therapy for prevention of falls in people with Parkinson's disease: a protocol for a randomised controlled trial and economic evaluation. BMC Neurol. 2009; 9:4. PMid:19161631 PMCid:PMC2637228. http://dx.doi.org/10.1186/1471-2377-9-4

22. Porter MM. Power training for older adults. Appl Physiol Nutr Metab. 2006;31(2):87-94. PMid:16604125.
23. Borg G. Perceived exertion as an indicator of somatic stress. Scand J Rehabil Med. 1970;2(2):92-8. PMid:5523831.

24. Ashburn A, Pickering RM, Fazakarley L, Ballinger C, McLellan DL, Fitton C. Recruitment to a clinical trial from the databases of specialists in Parkinson's disease. Parkinsonism Relat Disord. 2007;13(1):35-9. PMid:16928464.

25. Keus SHJ, Bloem BR, van Hilten JJ, Ashburn A, Munneke M. Effectiveness of physiotherapy in Parkinson's disease: the feasibility of a randomised controlled trial. Parkinsonism Relat Disord. 2007;13(2):115-21. PMid:17055767. http:// dx.doi.org/10.1016/j.parkreldis.2006.07.007

26. O’Brien M, Dodd KJ, Bilney B. A qualitative analysis of a progressive resistance exercise programme for people with Parkinson's disease. Disabil Rehabil. 2008;30(18):1350-7. PMid:18850350. http:// dx.doi.org/10.1080/09638280701614546

27. Scianni A, Teixeira-Salmela LF, Ada L. Challenges in recruitment, attendance and adherence of acute stroke survivors to a randomized trial in Brazil: a feasibility study. Rev Bras Fisioter. 2012;16(1):40-5. PMid:22218696. http://dx.doi.org/10.1590/S1413-35552012000100008

28. Ribeiro MCSA, Barata RB, Almeida MF, Silva ZP. Perfil sociodemográfico e padrão de utilização de serviços de saúde para usuários e não-usuários do SUS - PNAD 2003. Cien Saude Colet. 2006;11(4):1011-22. http://dx.doi. org/10.1590/S1413-81232006000400022

29. Gouveia GC, Souza WV, Luna CF, Souza-Júnior PRB, Szwarcwald CL. Satisfação dos usuários do sistema de saúde brasileiro: fatores associados e diferenças regionais. Rev Bras Epidemiol. 2009;12(3):281-96. http://dx.doi. org/10.1590/S1415-790X2009000300001

30. Hirsch MA, Toole T, Maitland CG, Rider RA. The effects of balance training and high-intensity resistance training on persons with idiopathic Parkinson's disease. Arch Phys Med Rehabil. 2003;84(8):1109-17. PMid:12917847.

31. Dibble LE, Hale TF, Marcus RL, Gerber JP, LaStayo PC. The safety and feasibility of high-force eccentric resistance exercise in persons with Parkinson's disease. Arch Phys Med Rehabil. 2006;87(9):1280-2. PMid:16935068, http:// dx.doi.org/10.1016/j.apmr.2006.05.016

32. Ahlskog JE, Muenter MD. Frequency of Levodopa-Related Dyskinesias and Motor Fluctuations as Estimated From the Cumulative Literature. Mov Disord. 2001;16(3):448-58. PMid:11391738. http://dx.doi.org/10.1002/mds.1090

33. Ettinger WH Jr, Burns R, Messier SP, Applegate W, Rejeski WJ, Morgan T, et al. A randomized trial comparing aerobic exercise and resistance exercise with a health education program in older adults with knee osteoarthritis. The fitness arthritis and seniors trial (FAST). JAMA. 1997;277(1):25-31. PMid:8980206. http://dx.doi. org/10.1001/jama.1997.03540250033028

34. Nègre-Pagès L, Regragui W, Bouhassira D, Grandjean H, Rascol O; DoPaMiP Study Group. Chronic pain in Parkinson's disease: the cross-sectional French 
DoPaMiP survey. Mov Disord. 2008;23(10):1361-9. PMid:18546344. http://dx.doi.org/10.1002/mds.22142

35. Michalowska M, Fiszer U, Krygowska-Wajs A, Owczarek K. Falls in Parkinson's disease. Causes and impact on patients' quality of life. Funct Neurol. 2005;20(4):163-8. PMid:16483454.

\section{Correspondence}

Fátima Rodrigues-de-Paula

Universidade Federal de Minas Gerais (UFMG)

Departamento de Fisioterapia

Av. Antônio Carlos, 6627

CEP 31210-901, Belo Horizonte, MG, Brasil

e-mail: fatimarp@globo.com; fatimarp@ufmg.br 